\title{
Chế định dẫn độ trong Bộ luật tố tụng hình sự 2015
}

\author{
Nguyễn Thị Ly* \\ Khoa Luật, Đại học Quốc gia Hà Nội, 144 Xuân Thủy, Cầu Giấy, Hà Nội, Việt Nam \\ Nhận ngày 01 tháng 11 năm 2017 \\ Chỉnh sửa ngày 25 tháng 11 năm 2017; Chấp nhận đăng ngày 18 tháng 12 năm 2017
}

\begin{abstract}
Tóm tắt: Bộ luật TTHS 2015 ra đời đã khắc phục những hạn chế của BLTTHS 2003, Luật tương trợ Tư pháp 2007 về dẫn độ trong TTHS. Bài viết này tập trung phân tích làm rõ nhu cầu, cơ sở căn cứ của việc sửa đổi bổ sung các qui định về dẫn độ của BLTTHS 2003, thông qua đó khẳng định sự cần thiết có BLTTHS mới thay thế, khắc phục những hạn chế của pháp luật về vấn đề này. Trên cơ sở đó luận giải những nội dung sửa đổi, bổ sung của BLTTHS 2015 về dẫn độ đáp ứng đòi hỏi của thực tiễn dẫn độ trong quá trình giải quyết vụ án hình sự có yếu tố nước ngoài.
\end{abstract}

Tư khóa: Bộ luật Tố tụng Hình sự năm 2015, dẫn độ, Hợp tác quốc tế trong tố tụng hình sự, điều kiện dẫn độ, thủ tục dẫn độ.

\section{Cơ sở, yêu cầu sửa đổi, bổ sung Bộ luật tố tụng hình sự năm 2003 về dẫn độ}

Những năm gần đây ở Việt Nam các tội phạm có tổ chức, xuyên quốc gia có diễn biến phức tạp, theo chiều hướng gia tăng, đặc biệt xuất hiện nhiều tội phạm mới như các tội phạm về tin học, rửa tiền, tội phạm sử dụng công nghệ cao..., các cơ quan tố tụng ngày càng phải xử lý nhiều hơn các vụ án hình sự có yếu tố nước ngoài và các cơ quan bảo vệ pháp luật của nước ngoài cũng phải xử lý nhiều vụ án hình sự liên quan đến người Việt Nam. Những điều này đã đặt ra nhu cầu hợp tác với các hoạt động hợp tác quốc tế trong quá trình giải quyết vụ án hình sự nhằm nâng cao hiệu quả của việc đấu tranh với tình trạng người nước ngoài phạm tội ở Việt Nam và người Việt Nam phạm tội ở nước ngoài, qua đó, góp phần thúc đẩy quá trình hội

\footnotetext{
* ĐT.: 84-973404816

Email: nguyenthily.hlu@gmail.com

https://doi.org/10.25073/2588-1167/vnuls.4127
}

nhập giữa nước ta với các nước trong khu vực và trên thế giới.

Bộ luật tố tụng hình sự năm 2003 của Việt Nam đã dành Phần VIII để quy định vấn đề hợp tác quốc tế, trong đó có chế định dẫn độ. Trước đó, vấn đề dẫn độ đã được quy định trong các Hiệp định tương trợ tư pháp và pháp lý về dân sự, hôn nhân gia đình và hình sự giữa Việt Nam với một số nước. Tuy nhiên, những quy định trong các Hiệp định tương trợ còn nhiều hạn chế, một số nội dung không còn phù hợp với xu thế và thực tiễn hợp tác quốc tế như: Quy định về dẫn độ, chuyển giao tài liệu hồ sơ vụ án; Quy định việc giải quyết vấn đề quốc tịch trong lĩnh vực tư pháp; vân đề hợp tác có đi có lại... trong đấu tranh xử lý tội phạm. Những quy định trong Bộ luật tố tụng hình sự năm 2003 về dẫn độ tội phạm cũng mới chỉ dừng lại ở mức khái quát, chưa cụ thể nên khó áp dụng trong quá trình giải quyết vụ án của các cơ quan tiến hành tố tụng. Những hạn chế của BLTTHS năm 2003 thể hiện ở các khía cạnh sau: (i) chưa xác định rõ ràng phạm vi điều chỉnh của Luật TTHS về 
dẫn độ. Dẫn độ được qui định ở nhiều văn bản pháp luật, trong đó chủ yếu là Luật tương trợ tư pháp năm 2007 và Phần thứ tám BLTTHS năm 2003 và cùng điều chỉnh nhiều nội dung của việc hợp tác quốc tế về hình sự nên đã dẫn đến những trùng lặp, thiếu đồng nhất, gây khó khăn khi áp dụng pháp luật. Bên cạnh đó lại thiếu những qui định về phạm vi dẫn độ; nguyên tắc dẫn độ; Vấn đề áp dụng pháp luật; Cơ quan trung ương trong hoạt động dẫn độ; Việc tiến hành tố tụng của người có thẩm quyền của Việt Nam ở nước ngoài và ngược lại; Trình tự, thủ tục xử lý trường hợp từ chối dẫn độ công dân Việt Nam; Căn cứ, thẩm quyền, trình tự, thủ tục áp dụng, hủy bỏ các biện pháp ngăn chặn để bảo đảm việc xem xét yêu cầu dẫn độ của nước ngoài hoặc thi hành quyết định dần độ...(ii) Pháp luật hiện hành về dẫn độ chưa có quy định về việc xử lý trường hợp từ chối dẫn độ công dân Việt Nam; (iii) chưa có quy định về thủ tục chuyển yêu cầu dẫn độ của Việt Nam cho phía nước ngoài. Mặc dù việc dẫn độ tội phạm được đảm bảo thực hiện theo hai chiều, tức là Việt Nam có thể là nước yêu cầu quốc gia khác dẫn độ người phạm tội hoặc thực hiện yêu cầu dẫn độ của quốc gia khác; (iv) chưa quy định tổng thời hạn cho toàn bộ quá trình tiếp nhận, xem xét, giải quyết yêu cầu dẫn độ của nước ngoài đối với Việt Nam mà chỉ quy định về thời hạn giải quyết yêu cầu dẫn độ theo phạm vi thẩm quyền của từng cơ quan. Thời hạn giải quyết yêu cầu về dẫn độ do đó có thể kéo dài hàng năm, gây khó khăn cho việc giải quyết vụ án của phía nước ngoài cũng như ảnh hưởng đến uy tín của Việt Nam trong quan hệ với các nước khác; (v) chưa chỉ rõ những biện pháp ngăn chặn nào có thể được áp dụng với người bị yêu cầu dẫn độ. Mặc dù Bộ luật tố tụng hình sự năm 2003 có quy định các biện pháp ngăn chặn gồm bắt, tạm giữ, tạm giam, cấm đi khỏi nơi cư trú, bảo lĩnh, đặt tiền hoặc tài sản có giá trị để bảo đảm, nhưng người bị yêu cầu dẫn độ là một chủ thể đặc biệt vì thường có liên quan đến yếu tố nước ngoài, do đó, các biện pháp ngăn chặn được áp dụng cũng cần phù hợp tránh sự tùy nghi gây ra những vi phạm về quyền con người [1, tr.97].
Bên cạnh đó, việc triển khai thực hiện các hiệp định đã được ký kết còn nhiều hạn chế, thiếu các văn bản hướng dẫn cần thiết, chưa có sự quan tâm chỉ đạo của các ngành chức năng liên quan dẫn đến tình trạng các quy định về dẫn độ ở Việt Nam còn mang nhiều tính hình thức; Năng lực, trình độ của cán bộ tiến hành tố tụng còn hạn chế là một trong những nguyên nhân làm cho việc thực thi pháp luật về dẫn độ tội phạm ở Việt Nam chưa đạt hiệu quả cao [2].

Trước thực trạng trên, yêu cầu hoàn thiện pháp luật về dẫn độ là đòi hỏi cấp thiết, thể hiện ở những khía cạnh sau: Thứ nhất, yêu cầu đấu tranh chống và phòng ngừa tội phạm, nhất là các tội phạm có tổ chức, xuyên quốc gia: Trước bối cảnh tình hình phát triển kinh tế, xã hội ở nước ta hiện nay, việc đấu tranh chống tội phạm có tổ chức xuyên quốc gia đang là một thách thức lớn trong tiến trình hội nhập kinh tế quốc tế. Điểm đặc biệt của tội phạm thời kỳ mới là sự biến hình của các tổ chức tội phạm quốc tế dưới hình thức các nhà đầu tư, các doanh nghiệp lớn, các đoàn ngoại giao... xâm nhập vào nước ta để thực hiện tội phạm hoặc chỉ huy các đối tượng ở Việt Nam thực hiện tội phạm. Chính những diễn biến phức tạp của tình hình tội phạm trong thời điểm giao thời của sự chuyển đổi nền kinh tế trong khi các cơ chế pháp luật của chúng ta còn nhiều kẽ hở có thể tạo cơ hội thuận lợi cho tội phạm phát triển đe dọa sự phát triển ổn định của xã hội; Thư hai,trong thời kỳ mới, việc hợp tác đấu tranh phòng chống tội phạm trở thành một nhu cầu tất yếu của các quốc gia, Việt Nam đã ký kết, phê chuẩn, gia nhập 38 điều ước quốc tế song phương và đa phương có quy định về dẫn độ (trong đó có 13 Hiệp định tương trợ tư pháp có nội dung dẫn độ, hiện nay 11 hiệp định đang có hiệu lực thi hành; 08 Hiệp định dẫn độ; 16 Điều ước quốc tế đa phương của Liên Hợp Quốc về đấu tranh phòng chống tội phạm nói chung và khủng bố quốc tế nói riêng và công ước của $A S E A N$ về chống khủng bố năm 2007), trong thời gian tới Việt Nam sẽ tiếp tục đàm phán ký kết các hiệp định song phương và đa phương về dẫn độ với các nước trong khu vực và trên thế giới. Do đó, để đảm bảo hiệu quả việc hợp tác quốc tế trong đấu tranh phòng 
chống tội phạm đòi hỏi Việt Nam cần nội luật hóa thể hiện những nội dung của các Điều ước quốc tế trong lĩnh vực dẫn độ tội phạm đã ký kết với các quốc gia, các tổ chức quốc tế; Thứ $b a$, BLTTHS 2003 và Luật tương trợ tư pháp năm 2007 cùng điều chỉnh vấn đề dẫn độ như một nội dung của việc hợp tác quốc tế về hình sự. Trong đó, BLTTHS mới chỉ quy định về cơ sơ pháp lý, mục đích và các trường hợp từ chối dẫn độ. Luật tương trợ tư pháp năm 2007 quy định chi tiết hơn vấn đề dẫn độ với vai trò là một trong các nội dung của tương trợ tư pháp về hình sự theo hướng kế thừa và bổ sung những quy định còn thiếu sót của Bộ luật tố tụng hình sự. Tuy nhiên, các nội dung về dần độ trong Luật này chưa đầy đủ, còn thiếu các quy định về dẫn độ đơn giản, bắt khẩn cấp trước khi có yêu cầu dẫn độ, các biện pháp ngăn chặn đối với người phạm tội bị dẫn độ, các quy định liên quan đến tội phạm chính trị, tội phạm quân sự, tội phạm chiến tranh, về cách xử lý người bị từ chối dẫn độ là công dân của nước được yêu cầu...Các thủ tục về dẫn độ chủ động trong trường hợp Việt Nam là nước yêu cầu dẫn độ cũng chưa được đề cập...Thư $t u$, Đối với các hiệp định về dẫn độ của Việt Nam với các nước, vấn đề dẫn độ được đề cập khá chi tiết, tuy nhiên bố cục của các hiệp định này còn thiếu sự đồng bộ cũng như tên gọi của các quy định, điều khoản chưa thống nhất $[1$, tr.87]. Thư năm, yêu cầu triển khai thực hiện các Nghị quyết của Đảng về chiến lược cải cách tư pháp. Nghị quyết Đại hội Đảng các khóa VII, IX, X và XI đã đưa ra những định hướng về cải cách bộ máy nhà nước trong đó có các cơ quan tư pháp. Trên cơ sở đó để tiếp tục quá trình cải cách tư pháp, ngày 2/1/2002, Bộ Chính trị đã ban hành Nghị quyết số $08-\mathrm{NQ} / \mathrm{TW}$ về "một số nhiệm vu trọng tâm công tác tu pháp trong thời gian tới", trước nhiệm vụ phát triển và bảo vệ đất nước, yêu cầu xây dựng Nhà nước pháp quyền Việt Nam XHCN. Ngày 2/6/2005, Bộ Chính trị đã ban hành Nghị quyết 49-NQ/TW về "Chiến luợc cải cách tu pháp đến năm 2020”. Nghị quyết nêu rõ các quan điểm chỉ đạo, phương hướng và nhiệm vụ cải cách tư pháp, trong đó có nội dung phải xác định rõ chức năng, nhiệm vụ, thẩm quyền và hoàn thiện tổ chức, bộ máy các cơ quan tư pháp.

Những phân tích nêu trên cho thấy," nhiều yêu cầu mới về hợp tác quốc tế trong Tố tụng hình sự đã nảy sinh trong thực tiễn và được ghi nhận trong nhiều điều ước quốc tế đa phương, song phương mà Việt Nam ký kết nhưng chưa được Bộ luật Tố tụng hình sự 2003 và Luật tương trợ Tư pháp 2007 điều chỉnh" [3, tr. 283].

\section{Những nội dung của Bộ luật Tố tụng Hình sự năm 2015 về dẩn độ}

Bộ luật Tố tụng hình sự năm 2015 đã giải quyết cơ bản được những yêu cầu nêu trên thể hiện ở những nội dung sau:

\section{(i) Về phạm vi điều chỉnh của Hợp tác quốc tế trong tố tưng hình sư}

Bộ Luật TTHS năm 2003 không quy định về phạm vi của hợp tác quốc tế trong tố tụng hình sự, Phần VIII Bộ luật này chỉ tập trung vào hai nội dung chính là dẫn độ, chuyển giao hồ sơ, tài liệu, vật chứng của vụ án. Quy định như vậy vừa thiếu sự rõ ràng, vừa có thể gây trùng lặp với quy định về tương trợ tư pháp trong các văn bản quy phạm pháp luật khác (chẳng hạn như Luật tương trợ tư pháp). BLTTHS năm 2015 đã quy định cụ thể phạm vi của hợp tác quốc tế trong tố tụng hình sự tại Điều 485 . Theo đó: a. Hợp tác quốc tế trong tố tụng hình sự là việc các cơ quan tiến hành tố tụng có thẩm quyền của nước Cộng hòa xã hội chủ nghĩa Việt Nam và các cơ quan có thẩm quyền của nước ngoài phối hợp, hỗ trợ nhau để thực hiện các hoạt động phục vụ yêu cầu điều tra, truy tố, xét xử và thi hành án hình sự. b. Hợp tác quốc tế trong tố tụng hình sự bao gồm: Tương trợ tư pháp về hình sự; dẫn độ; tiếp nhận, chuyển giao người đang chấp hành hình phạt tù và các hoạt động hợp tác quốc tế khác được quy định tại Bộ luật này, pháp luật về tương trợ tư pháp hình sự và các điều ước quốc tế mà Việt Nam là thành viên hoặc thực hiện trên nguyên tắc có đi có lại. c. Hợp tác quốc tế trong tố tụng hình sự trên lãnh thổ Việt Nam được thực hiện theo quy 
định của BLTTHS 2015, Luật tương trợ tư pháp và các quy định khác của pháp luật Việt Nam có liên quan.

Các quy định này đã làm rõ được phạm vi của vấn đề hợp tác quốc tế trong tố tụng hình sự bằng cách đưa ra khái niệm, nội dung và nguồn của phần hợp tác quốc tế. Theo đó, dẫn độ là một chế định độc lập của hợp tác quốc tế trong tố tụng hình sự bên cạnh các chế định khác là tương trợ tư pháp về hình sự; tiếp nhận, chuyển giao người đang chấp hành hình phạt tù và các hoạt động hợp tác quốc tế khác. Với quy định này, nội dung của hợp tác quốc tế đã được xác định cụ thể, rõ ràng hơn so với quy định trong BLTTHS 2003, tránh nhầm lẫn quan điểm dẫn độ là nội dung của tương trợ tư pháp về hình sự.

\section{(ii) Nguồn luật áp dụng}

Nguồn luật là một nội dung quan trọng nhằm xác định cơ sở pháp lý cho việc áp dụng pháp luật. Việc quy định nguồn luật giúp cho quá trình áp dụng pháp luật diễn ra thuận lợi. Như đã đề cập, chế định dần độ tội phạm trong hệ thống pháp luật nước ta được quy định ở Bộ luật TTHS, luật tương trợ tư pháp và các hiệp định có nội dung về dẫn độ mà Việt Nam đã ký kết với các nước, tuy nhiên, Bộ luật tố tụng hình sự năm 2003 không có quy định rõ phạm vi áp dụng của các văn bản này với chế định dẫn độ. Để khắc phục hạn chế này, Bộ luật TTHS năm 2015 đã bổ sung một điều khoản quy định về nguồn luật áp dụng với phần hợp tác quốc tế trong tố tụng hình sự Việt Nam, cụ thể: Hợp tác quốc tế trong tố tụng hình sự trên lãnh thổ Việt Nam được thực hiện theo quy định của BLTTHS 2015, Luật tương trợ tư pháp và các quy định khác của pháp luật Việt Nam có liên quan.

\section{(iii) Nguyên tắc dẫn độ}

Bộ luật tố tụng hình sự năm 2015 quy định về nguyên tắc hợp tác quốc tế trên cơ sở kế thừa quy định về nguyên tắc hợp tác quốc tế trong BLTTHS 2003 theo hướng ngắn gọn và chính xác hơn. Cụ thể, tại Điều 492 BLTTHS 2015 quy định vấn đề hợp tác quốc tế trong tố tụng hình sư được thưc hiện trên nguyên tắc tôn trọng độc lạp, chu quyền, toàn vẹn lãnh thổ quốc gia, không can thiệp vào công việc nội bộ của nhau, bình đẳng và cùng có lợ, phù hợp với Hiến pháp, pháp luật của nước Cộng hòa xã hội chủ nghĩa Việt Nam và điều ước quốc tế mà Việt Nam là thành viên. Đối chiếu với BLTTHS năm 2003, BLTTHS 2015 đã bỏ đi nội dung "phù hợp với nguyên tắc co bản của luật quốc tế". Chúng tôi cho rằng, việc lược bỏ đi nội dung này là hợp lý vì qua thực tiễn nghiên cứu các quy định về dẫn độ cho thấy, các quy định của nội luật về dẫn độ đã được ban hành trên cơ sở phù hợp với pháp luật quốc tế, thêm vào đó khi ký kết các điều ước về dẫn độ với các nước thì việc cụ thể hóa hoặc thừa nhận các nguyên tắc cơ bản của luật quốc tế đã được ghi nhận trong những văn bản này nên có thể thấy quy định việc hợp tác quốc tế trong tố tụng hình sự nói chung hay trong lĩnh vực dẫn độ nói riêng phải phù hợp với các nguyên tắc cơ bản của luật quốc tế là không cần thiết.

Bên cạnh đó, luật cũng quy định nguyên tắc hợp tác quốc tế khi Việt Nam chưa ký kết các điều ước quốc tế được dựa trên nguyên tắc có đi có lại nhưng không được trái với quy định của nước Cộng hòa xã hội chủ nghĩa Việt Nam, phù hợp pháp luật quốc tế và tập quán quốc tế.

\section{(iv) Quy định mói về co quan trung uơng trong dần độ}

Điểm đặc trưng của dẫn độ tội phạm là quan hệ hợp tác giữa hai quốc gia (nước yêu cầu và nước được yêu cầu), do đó, bên cạnh những thủ tục tố tụng thông thường của tố tụng hình sự, dẫn độ còn có các hoạt động ngoại giao giữa nước yêu cầu và nước được yêu cầu và vì thế dẫn độ còn chịu sự điều chỉnh của các quy tắc về ngoại giao và hợp tác quốc tế khác. Trong quan hệ hợp tác quốc tế, pháp luật nước ta đã quy định một cơ quan trung ương phụ trách trực tiếp có vai trò đầu mối trong việc thực hiện một lĩnh vực cụ thể. Trong lĩnh vực dẫn độ, Nhà nước ta quy định Bộ công an là cơ quan trung ương giữ vai trò đầu mối và chỉ đạo thực hiện các hoạt động về dẫn độ. Trách nhiệm cụ thể của Bộ công an đã được quy định tại 
Điều 65 Luật tương trợ tư pháp 2007, tuy nhiên dẫn độ là một nội dung của hợp tác quốc tế nên những quy định chung bao gồm việc xác định cơ quan trung ương trong hoạt động dẫn độ cần được quy định trong Bộ luật tố tụng hình sự là cần thiết. BLTTHS năm 2003 không quy định về vấn đề này nên đã được bổ sung trong Bộ luật TTHS năm 2015 tại Điều 495 cu thể như sau: "Bộ Công an là Co quan Trung urong của nuớc Cộng hòa xã họi chủ nghĩa Việt Nam trong hoạt động dẫn độ và chuyển giao người đang chấp hành án phạt tù ”.

Theo đó, quy định trên chỉ nêu ra vị trí mà không quy định chi tiết những nội dung về vai trò của Bộ công an với tư cách là cơ quan trung ương trong hoạt động dẫn độ. Theo chúng tôi quy định như vậy là hợp lý, đúng với định hướng sửa đổi bộ luật tố tụng hình sự năm 2003. Do đó, BLTTHS 2015 chỉ quy định những nguyên tắc chung về dẫn độ và những nội dung về dẫn độ mà Luật tương trợ tư pháp chưa quy định. Trong trường hợp này, vai trò cụ thể của Bộ công an đã được quy định tại Điều 65 Luật tương trợ tư pháp năm 2007 nên không cần thiết phải đưa vào Bộ luật TTHS nữa.

(vi) Quy định về việc tiến hành tố tụng của người có thẩm quyền của Việt Nam ở nuớc ngoài và người có thẩm quyền của nước ngoài ơ Việt Nam

Hoạt động dẫn độ bao gồm các trình tự tố tụng được thực hiện ở cả nước yêu cầu và nước được yểu cầu, với trở ngại về lãnh thổ nên không phải lúc nào hoạt động dẫn độ cũng được tiến hành thuận lợi vì các cơ quan có thẩm quyền của nước ta không thể trực tiếp tham gia vào các hoạt động tố tụng để giải quyết yêu cầu dẫn độ ở nước sở tại và ngược lại. Để giải quyết vấn đề này, đòi hỏi các quốc gia trong quan hệ dẫn độ cần thừa nhận vai trò và quy định trách nhiệm của những cơ quan, người có thẩm quyền của nước mình đang ở nước đối tác để đảm nhận một số nhiệm vụ liên quan đến dẫn độ, những người này không trực tiếp tham gia vào vệc giải quyết yêu cầu dẫn độ nhưng có thể đóng vai trò trung gian để truyền tải các nội dung liên quan đến quá trình giải quyết các yêu cầu về dẫn độ. Thực tế dẫn độ cũng đã cho thấy, việc thực hiện dẫn độ sẽ được tiến hành thuận lợi hơn khi có sự tham gia của những người có thẩm quyền của Việt Nam ở nước ngoài hay người của thẩm quyền của nước ngoài ở Việt Nam, trong một số trường hợp những cán bộ làm việc tại các cơ quan đại diện của Việt Nam ở nước ngoài như Đại sứ quán, lãnh sự quán có thể đóng vai trò tiểp nhận và truyền đạt các vấn đề phát sinh trong quá trình dẫn độ giữa nước yêu cầu và nước được yêu cầu hoặc tham gia vào quá trình giải quyết dẫn độ tại nước sở tại, đại diện quyền cho người bị dần độ là công dân Việt Nam ở nước sở tại.... Nhận thấy tầm quan trọng của việc tiến hành tố tụng của người có thẩm quyền của Việt Nam ở nước ngoài và ngược lại, một số hiệp định tương trợ tư pháp của Việt Nam với các nước ký kết trong thời gian gần đây đã đề cập đến vấn đề này nhưng cả BLTTHS 2003 và Luật tương trợ tư pháp năm 2007 đều chưa quy định. Sự thiếu qui định cụ thể vấn đề này đã ảnh hưởng đến quá trình thi hành pháp luật do không có cơ sở pháp lý về thẩm quyền, trách nhiệm của người có thẩm quyền của Việt Nam ở nước ngoài cũng như không có cơ sở để những người có thẩm quyền của nước ngoài ở Việt Nam được tham gia vào quá trình giải quyết các yêu cầu về dẫn độ. Khắc phục hạn chế này, Bộ luật TTHS 2015 đã bổ sung Điều 495 với quy định "Việc tiến hành tố tụng của người có thẩm quyền của Việt Nam ở nước ngoài và người có thẩm quyền của nước ngoài ơ Việt Nam đuoơc thưc hiện theo quy định của các điều ước quốc tế mà Việt Nam là thành viên hoặc thục hiện trên nguyên tắc có đi có lại”.

Quy định trên đã thừa nhận vai trò của những người có thẩm quyền của Việt Nam ở nước ngoài và người có thẩm quyền của nước ngoài ở Việt Nam, đồng thời quy định cơ sở để những chủ thể này thực hiện các hoạt động tố tụng liên quan đến dẫn độ là các điều ước quốc tế mà Việt Nam là thành viên hoặc được thực hiện trên nguyên tắc có đi có lại. 
(vii) Xủ lý trương hợp tù chối dẫn độ công dân Việt Nam

Bộ luật tố tụng hình sự năm 2015 đã bỏ quy định về các trường hợp từ chối dẫn độ được quy định tại điều 343 BLTTHS năm 2003, đồng thời bổ sung quy định về việc xử lý trường hợp từ chối dẫn độ công dân Việt Nam. Thực tế, các trường hợp từ chối dẫn độ đã được cụ thể hóa tại Luật tương trợ tư pháp năm 2007 (Điều 35), việc 2 đạo luật cùng quy định về vấn đề này đã tạo ra sự trùng lặp và không đảm bảo tính thống nhất của hệ thống pháp luật, thêm vào đó, quy định về các trường hợp từ chối dẫn độ không phải là quy định mang tính cơ sở và nguyên tắc nên không cần thiết phải đưa vào Bộ luật TTHS, hầu hết các điều ước quốc tế về dẫn độ mà Việt Nam ký kết với các nước cũng đã có quy định chi tiết về vấn đề này. Do đó, việc bỏ đi quy định về các trường hợp từ chối dẫn độ trong BLTTHS năm 2015 là phù hợp với hệ thống các văn bản pháp luật có quy định về dẫn độ ở nước ta hiện nay.

Đối với trường hợp từ chối dẫn độ công dân, đây được coi là trường hợp từ chối dẫn độ bắt buộc theo pháp luật Việt Nam và nhiều quốc gia trên thế giới. Tuy nhiên, trong khi luật dẫn độ quốc tế quy định nước từ chối dẫn độ công dân của mình phải giao công dân đó cho cơ quan có thẩm quyền của nước mình tiến hành các thủ tục tố tụng nhằm xác minh tội phạm thì luật của Việt Nam chưa có quy định để giải quyết trường hợp này. Do đó, trong nhiều trường hợp khi Việt Nam từ chối dẫn độ công dân của mình cho nước ngoài thì cũng không có căn cứ pháp lý để tiếp tục xử lý đối với người bị từ chối dẫn độ. Đây là lỗ hổng pháp lý có thể gây ra tình trạng bỏ lọt tội phạm vì thực tế người bị từ chối dần độ có thể đã thực hiện tội phạm được nêu trong yêu cầu dẫn độ và dù không bị dẫn độ cho nước ngoài thì cũng cần bị xử lý như những trường hợp phạm tội khác để đảm bảo tính công bằng và không bỏ lọt tội phạm. Khắc phục tình trạng này, BLTTHS 2015 bổ sung quy định về việc xử lý trường hợp từ chối dẫn độ công dân Việt Nam. Theo đó, khi từ chối dẫn độ mà cơ quan có thẩm quyền nước ngoài có yêu cầu thì cơ quan tiến hành tố tụng có thẩm quyền của nước Cộng hòa xã hội chủ nghĩa Việt Nam có trách nhiệm xem xét để truy cứu trách nhiệm hình sự hoặc cho thi hành bản án, quyết định hình sự của Tòa án nước ngoài đối với công dân Việt Nam bị từ chối dẫn độ.

Song song với việc quy định xử lý trường hợp dẫn độ công dân Việt Nam, BLTTHS 2015 cũng bổ sung quy định về trình tự, thủ tục xem xét, xử lý yêu cầu truy cứu trách nhiệm hình sự đối với công dân Việt Nam bị từ chối dẫn độ.

(vii) Điều kiện cho thi hành bản án, quyết định hình sư của Tòa án nuớc ngoài đối với công dân Việt Nam bị tù chối dẫn độ

Đây là một quy định mới của BLTTHS 2015 mà những BLTTHS trước đây cũng như các văn bản liên quan chưa quy định. Xuất phát từ nhu cầu thực tiễn, trong quan hệ dẫn độ có nhiều trường hợp có căn cứ xác minh công dân Việt Nam bị từ chối dẫn độ đã thực hiện một tội phạm và đã được tòa án nước ngoài tuyên một quyết định hay một bản án có hiệu lực pháp luật thì cơ quan có thẩm quyền của Việt Nam có thể cho áp dụng quyết định hoặc bản án đã có hiệu lực đó đối với người bị từ chối dẫn độ. Quy định này về cơ bản là phù hợp với thực tiễn quan hệ dẫn độ giữa các quốc gia, thừa nhận bản chất của việc từ chối dẫn độ là không làm mất đi trách nhiệm hình sự của người phạm tội về tội phạm mà người đó đã thực hiện, loại bỏ những thủ tục tố tụng không cần thiết đồng thời thể hiện sự tôn trọng của nước từ chối dẫn độ với các phán quyết của các cơ quan tiến hành tố tụng nước ngoài. Tuy nhiên, không phải mọi bản án, quyết định hình sự của tòa án nước ngoài đối với công dân Việt Nam bị từ chối dẫn độ đều được chấp nhận cho thi hành tại Việt Nam, việc cho thi hành những bản án, quyết định này phải đảm bảo những điều kiện nhất định. Cụ thể, tại Điều 500 BLTTHS 2015 đã quy định cụ thể điều kiện để bản án, quyết định hình sự của Tòa án nước ngoài đối với công dân Việt Nam bị từ chối dẫn độ có thể được thi hành tại Việt Nam. Đó là các điều kiện: 
a. Điều kiện tiên quyết để cho thi hành bản án, quyết định của tòa án ở nước ngoài đối với công dân bị từ chối dẫn độ ở Việt Nam là phải có văn bản yêu cầu của cơ quan có thẩm quyền của nước ngoài. Điều kiện này theo chúng tôi là hợp lý vì thực tế thì bản án hay quyết định được đề nghị cho thi hành là của Tòa án nước ngoài nên việc áp dụng quyết định hay bản án này phải thể hiện được ý kiến của cơ quan có thẩm quyền nước ngoài. Mặt khác, nhằm bảo đảm sự bảo hộ cao nhất của Nhà nước với công dân của mình, thông thường cơ quan có thẩm quyền của Việt Nam vẫn phải tiến hành các thủ tục tố tụng cần thiết đối với công dân Việt Nam bị từ chối dẫn độ trên cơ sở tôn trọng sự thật khách quan và đảm bảo quyền và lợi ích hợp pháp của công dân của mình (bao gồm những quyền và lợi ích mà theo quyết định hay bản án của Tòa án nước ngoài công dân Việt Nam có thể không được hưởng). Do đó, việc cho thi hành quyết định hình sự hay bản án của Tòa án nước ngoài không nên được áp dụng một cách hiển nhiên đối với công dân Việt Nam bị từ chối dẫn độ mà chỉ được xem xét áp dụng khi có đề nghị của cơ quan có thẩm quyền của nước ngoài.

b. Điều kiện thứ hai để cho thi hành quyết định hình sự hay bản án có hiệu lực pháp luật của Tòa án nước ngoài đối với công dân Việt Nam bị từ chối dẫn độ là hành vi phạm tội mà công dân Việt Nam bị kết án ở nước ngoài cũng được cấu thành tội phạm theo quy định của Bộ luật hình sự của nước Cộng hòa xã hội chủ nghĩa Việt Nam. Quy định này được xây dựng trên cơ sở nguyên tắc định tội danh kép trong dẫn độ, đồng thời đảm bảo nguyên tắc chỉ một người phạm một tội được quy định trong BLHS của Việt Nam mới bị coi là tội phạm. Theo đó, nếu hành vi mà công dân Việt Nam đã thực hiện không cấu thành tội phạm theo BLHS nước ta (mặc dù theo luật hình sự nước yêu cầu người này phạm tội) thì không có cơ sở để truy cứu TNHS đối với người đó về tội phạm mà nước yêu cầu đã thực hiện và theo đó cũng không có căn cứ để buộc người bị từ chối dẫn độ phải thực hiện quyết định hay bản án của Tòa án nước ngoài. c. Điều kiện thứ ba là bản án, quyết định hình sự của Tòa án nước ngoài được cho thi hành đối với công dân Việt nam bị từ chối dẫn độ phải là các văn bản đã có hiệu lực pháp luật. Theo quy định của pháp luật Việt Nam, quyết định, bản án chưa có hiệu lực pháp luật thì sẽ không cho thi hành đối với người phạm tội vì trong thời gian này quyết định, bản án có thể bị kháng cáo hoặc kháng nghị theo đề nghị của các chủ thể có thẩm quyền và do đó quyết định hoặc bản án đã được tuyên với người phạm tội có thể bị thay đổi. Khi quyết định cho thi hành bản án, quyết định hình sự của Tòa án nước ngoài, điều kiện này cần được đảm bảo nhằm tránh những thay đồi có thể xảy ra trong quá trình thi hành án và đảm bảo sự phù hợp với quy định của pháp luật Việt Nam.

Bên cạnh các quy định về điều kiện cho thi hành bản án, quyết định hình sự của Tòa án nước ngoài với công dân Việt Nam bị từ chối dẫn độ, BLTTHS cũng bổ sung các quy định về trình tự, thủ tục xem xét yêu cầu thi hành bản án, quyết định hình sự của Tòa án nước ngoài đối với trường hợp từ chối dẫn độ này.

\section{(viii) Quy định về việc áp dụng các biện pháp ngăn chặn trong dẫn độ}

Biện pháp ngăn chặn được sử dụng nhằm bảo đảm cho việc xem xét yêu cầu dần độ hoặc thi hành quyết định dẫn độ. Về vấn đề này, Luật tương trợ tư pháp năm 2007 đã quy định cơ quan có thẩm quyền của Việt Nam có thể áp dụng các biện pháp ngăn chặn theo quy định của pháp luật Việt Nam và điều ước quốc tế mà Việt Nam là thành viên khi nhận được yêu cầu dẫn độ chính thức. Có thể nhận thấy rằng, quy định này mới chỉ mang tính định hướng mà chưa quy định rõ những biện pháp ngăn chặn nào có thể được áp dụng đối với người bị yêu cầu dẫn độ. Theo thực tiễn áp dụng pháp luật thì các biện pháp ngăn chặn áp dụng đối với các trường hợp dẫn độ thường được hiểu là các biện pháp ngăn chặn áp dụng chung trong BLTTHS 2003. Tuy nhiên với cách lý giải dẫn độ là một hoạt động tố tụng đặc biệt mà quá trình giải quyết yêu cầu dẫn độ có liên quan đến hệ thổng pháp luật của nhiều quốc gia thì cần quy định 
cụ thể các biện pháp ngăn chặn có thể được áp dụng với người bị yêu cầu dẫn độ. Để khắc phục hạn chế này BLTTHS năm 2015 đã quy định về các biện pháp ngăn chặn đối với người bị yêu cầu dẫn độ tại Điều 502 BLTTHS gồm bắt, tạm giam, cấm đi khỏi nơi cư trú, đặt tiền để bảo đảm, tạm hoãn xuất cảnh. Điều luật này cũng quy định về căn cứ và thẩm quyền áp dụng biện pháp ngăn chặn, cụ thể như sau: $a$.Về căn cú áp dưng: Biện pháp ngăn chặn chỉ được áp dụng đối với người bị xem xét yêu cầu dần độ hoặc bị dẫn độ khi có đủ những điều kiện: Tòa án đã có quyết định xem xét yêu cầu dẫn độ đối với người đó hoặc quyết định dẫn độ đối với người đó đã có hiệu lực pháp luật; Có căn cứ cho rằng người bị yêu cầu dẫn độ bỏ trốn hoặc gây khó khăn, cản trở việc xem xét yêu cầu dẫn độ hoặc thi hành quyết định dẫn độ. $b$. Về thẩm quyền: Chánh án, Phó Chánh án Tòa án nhân dân cấp tỉnh; Chánh án, Phó Chánh án Tòa án nhân dân cấp cao quyết định việc áp dụng các biện pháp ngăn chặn quy định. Thẩm phán được phân công chủ tọa phiên họp xem xét yêu cầu dẫn độ có quyền quyết định việc áp dụng biện pháp cấm đi khỏi nơi cư trú, biện pháp đặt tiền để bảo đảm sự có mặt của người bị yêu cầu dẫn độ tại phiên họp. Thủ tục áp dụng biện pháp đối với các biện pháp ngăn chặn được qui định cụ thể như sau:

Biện pháp bắt, tạm giam ngườ bi yêu cầu dẫn độ (Điều 503 BLTTHS 2015)

Bắt, tạm giam người bị yêu cầu dẫn độ là một trong những biện pháp ngăn chặn được áp dụng trong hoạt động dẫn độ tội phạm. Theo đó, nếu cơ quan tiến hành tố tựng nhận thấy cần thiết phải bắt người bị yêu cầu dẫn độ để việc xem xét và giải quyết yêu cầu dẫn độ được đảm bảo thì có thể ra quyết định bắt người bị yêu cầu dẫn độ để tạm giam. Trình tự, thủ tục bắt, tạm giam người bị yêu cầu dẫn độ về cơ bản được thực hiện giống như việc bắt bị can, bị cáo để tạm giam theo quy định của BLTTHS, tuy nhiên, khi bắt người bị yêu cầu dẫn độ cần chú ý thời hạn tạm giam để xem xét yêu cầu dẫn độ không được vượt quá thời hạn giam giữ trong lệnh bắt, giam giữ của cơ quan có thẩm quyền của nước yêu cầu dẫn độ hoặc thời hạn phải thi hành hoặc còn phải thi hành hình phạt tù trong bản án, quyết định hình sự của Tòa án nước yêu cầu dẫn độ. Về cơ bản, thời hạn tạm giam không thể vượt quá thời hạn phạt tù mà người phạm tội có thể bị áp dụng do hành vi phạm tội của mình gây ra. Do đó, khi quyết định thời hạn tạm giam với người bị yêu cầu dẫn độ, cơ quan có thẩm quyền của Việt Nam phải xem xét sự phù hợp về thời hạn tạm giam theo pháp luật của hai nước nhằm đảm bảo thời hạn đó không vượt quá thời hạn mà người bị yêu cầu dẫn độ phải thi hành hoặc còn phải thi hành theo pháp luật của nước yêu cầu dẫn độ.

Trong một số trường hợp cần thiết như vụ án có tính chất phức tạp, hoặc người bị yêu cầu dẫn độ bỏ trốn...thì thời hạn tạm giam có thể được gia hạn theo đề nghị của nước được yêu cầu để đảm bảo việc xem xét yêu cầu dẫn độ.

Biện pháp cấm đi khỏi nơ cu trú, tạm hoãn xuất cảnh (Điều 504 BLTTHS 2015)

Cấm đi khỏi nơi cư trú là biện pháp ngăn chặn có thể được áp dụng đối với người bị yêu cầu dẫn độ có nơi cư trú rõ ràng nhằm bảo đảm sự có mặt của họ theo giấy triệu tập của Toà án.

Tạm hoãn xuất cảnh là biện pháp ngăn chặn có thể được áp dụng đối với người bị yêu cầu dẫn độ nhằm bảo đảm sự có mặt của họ theo giấy triệu tập của Toà án.

Về thủ tục, việc áp dụng biện pháp cấm đi khỏi nơi cư trú và biện pháp tạm hoãn xuất cảnh được thực hiện tương tự như trường hợp với bị can, bị cáo. Tuy nhiên, thời hạn áp dụng biện pháp cấm đi khỏi nơi cư trú hay thời hạn áp dụng biện pháp tạm hoãn xuất cảnh không được vượt quá thời hạn bảo đảm việc xem xét yêu cầu dẫn độ và thời hạn xem xét kháng cáo, kháng nghị đối với quyết định dẫn độ hoặc quyết định từ chối dẫn độ theo quy định của Luật tương trợ tư pháp.

Biện pháp đặt tiền để đảm bảo (Điều 505 BLTTHS 2015)

Đặt tiền để bảo đảm là biện pháp ngăn chặn có thể được áp dụng đối với người bị yêu cầu dẫn độ căn cứ vào tình trạng tài sản của người 
đó nhằm bảo đảm sự có mặt của họ theo giấy triệu tập của Tòa án. Trình tự, thủ tục áp dụng biện pháp này được thực hiện tương tự như đối với bị can, bị cáo theo quy định của BLTTHS. Tuy nhiên, thời hạn áp dụng biện pháp đặt tiền để bảo đảm không được vượt quá thời hạn đảm bảo việc xem xét yêu cầu dẫn độ và thời hạn xem xét kháng cáo, kháng nghị đối với quyết định dẫn độ hoặc quyết định từ chối dẫn độ theo quy định của Luật tương trợ tư pháp.

Như vậy, có thể thấy, về trình tự thủ tục áp dụng các biện pháp ngăn chặn đối với người bị yêu cầu dẫn độ được thực hiện tương tự như trình tự, thủ tục áp dụng biện pháp ngăn chặn đối với bị can, bị cáo theo quy định của BLTTHS. Điểm khác biệt trong việc áp dụng các biện pháp ngăn chặn đối với người bị yêu cầu dẫn độ là thời hạn. Theo đó, căn cứ vào quy định của pháp luật hai nước về thời hạn áp dụng các biện pháp ngăn chặn mà cơ quan có thẩm quyền của Việt Nam ra quyết định áp dụng biện pháp ngăn chặn với người bị yêu cầu dần độ với thời hạn cụ thể.

\section{Tài liệu tham khảo}

[1] Nguyễn Thị Ly, Luận văn thạc sĩ "Chế định dẫn độ trong hợp tác quốc tế theo luật Tố tụng hình sự Việt Nam”, năm 2015.

[2] Bộ Công An (2014), Báo cáo tổng kết 06 năm thi hành Luật tương trợ tư pháp trong lĩnh vực dẫn độ, chuyển giao người bị kết án phạt tù của Bộ Công an từ 01/07/2008 đến 31/06/2014, Hà Nội.

[3] Nguyễn Hòa Bình, Những nội dung mới của Bộ luật Tố tụng hình sự 2015, Nhà xuất bản Chính trị Quốc gia, Hà Nội 2016.

\title{
Extradition Provisions in the 2015 Criminal Procedure Code
}

\author{
Nguyen Thi Ly \\ VNU School of Law, 144 Xuan Thuy, Cau Giay, Hanoi, Vietnam
}

\begin{abstract}
The 2015 Criminal Procedure Code eliminates the limitations of the 2003 Criminal Procedure Code, the 2007 Law on Mutual Legal Assistance for extradition in the criminal procedure. This article focuses on clarifying the need, the basis for amending the extradition provisions of the 2003 Criminal Procedure Code, thereby confirming the need to replace the 2003 Criminal Procedure Code by the 2015 Criminal Procedure Code, to overcome the limitations of the law on this matter. On that basis, the paper clarifies the contents of the amendment and supplement to the 2015 Criminal Procedure Code on extradition to satisfy the requirement of extradition practice in the process of criminal cases involving foreign elements.
\end{abstract}

Keywords: The 2015 Criminal Procedure Code, extradition, international cooperation in criminal procedure, conditions of extradition, extradition procedure 